\title{
Influence of the concrete properties in the effectiveness of the NSM CFRP laminates for the shear strengthening of RC beams
}

\author{
Salvador Dias (sdias@civil.uminho.pt) \& Joaquim Barros \\ ISISE, University of Minho, Guimarães, Portugal
}

ABSTRACT: The New Surface Mounted (NSM) technique was applied to increase the shear resistance of Reinforced Concrete (RC) beams. For this purpose, laminates of Carbon Fiber Reinforced Polymer (CFRP) were introduced into thin slits made on the concrete cover of the lateral faces of the beams to be strengthened. In the present paper the influence of concrete strength on the effectiveness of the NSM technique is assessed by an experimental program. From the obtained results it can be concluded that the NSM shear strengthening technique with CFRP laminates is still effective in RC beams with low concrete strength. However, as minimum is the concrete strength as less effective is the NSM technique.

\section{EXPERIMENTAL PROGRAM}

The influence of the concrete mechanical properties on the performance of the NSM technique using CFRP laminates for the shear strengthening of RC beams (Fig. 1) is assessed by experimental research, which main features are presented in this publication.
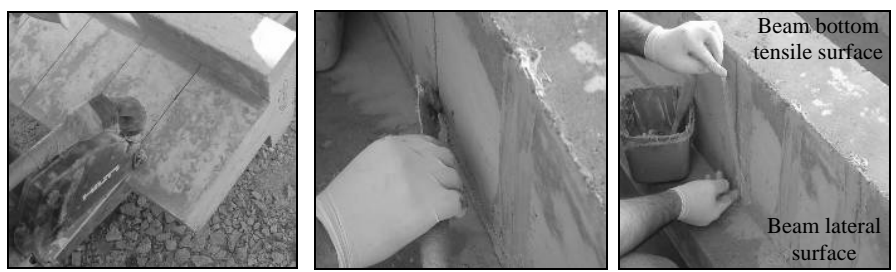

Figure 1. NSM technique with CFRP laminates for the shear strengthening of RC beams.

\subsection{Test series and materials properties}

Figure 2 presents the $\mathrm{T}$ cross section beam prototype used in the experimental program. The reinforcement systems were designed to assure that all the tested beams failed in shear. To localize shear failure in only one of the beam shear spans, a three point load configuration of a distinct length of the beam shear spans was selected. To avoid shear failure in the $\mathrm{L}_{\mathrm{r}}$ beam span, steel stirrups $\phi 6 @ 75 \mathrm{~mm}$ were applied in this span. In terms of the shear reinforcement systems the differences between the tested beams were localized in the $\mathrm{L}_{\mathrm{i}}$ beam span. Five arrangements of NSM CFRP laminates were used in RC beams that were manufactured with a concrete of a compressive strength at the age of beam tests of 39.7 $\mathrm{MPa}\left(f_{c m}=39.7 \mathrm{MPa}\right)$ and 18.6 $\operatorname{MPa}\left(f_{c m}=18.6 \mathrm{MPa}\right)$. The differences between the beams with $f_{c m}=39.7 \mathrm{MPa}$ and the beams with $f_{c m}=$ 18.6 $\mathrm{MPa}$ are restricted to the mode of preventing brittle spalling of the concrete cover at the supports (Fig. 2). To overcome the difficulties to bend $\phi 32$ mm longitudinal tensile bars, their ends were welded to steel plates in the beams with the lower concrete strength (Fig. 2).
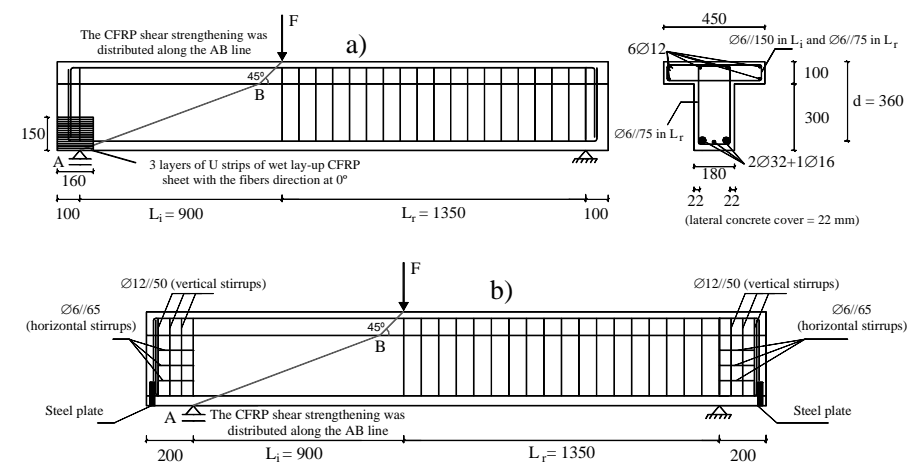

Figure 2. Geometry and steel reinforcements applied in all tested beams (dimensions in $\mathrm{mm}$ ): a) beams with $f_{c m}=39.7$ $\mathrm{MPa}$ and b) beams with $f_{c m}=18.6 \mathrm{MPa}$.

For each type of concrete five arrangements of NSM CFRP laminates were applied in five RC beams with a percentage of steel stirrups of $0.10 \%$ $\left(\rho_{s w}=0.10 \%\right)$, and in five RC beams with a percentage of steel stirrups of $0.17 \%\left(\rho_{s w}=0.17 \%\right)$. Three distinct inclinations of CFRP laminates $\left(45^{\circ}, 60^{\circ}\right.$ and $90^{\circ}$ ) were studied and, for inclined laminates, two levels of CFRP percentage $\left(\rho_{f}\right)$ were analyzed (Table 1 and Fig. 3). For both percentages of CFRP, the spacing of laminates for each inclination was ob- 
tained with the purpose that the shear strengthening contribution of the CFRP would be similar (Dias and Barros 2009).

The three point beam bending tests (Fig. 2) were carried out using a servo closed-loop control equipment, taking the signal read in the displacement transducer, placed at the loaded section, to control the test at a deflection rate of $0.01 \mathrm{~mm} / \mathrm{second}$.

The concrete compressive strength was evaluated at 28 days and at the age of the beam tests, carrying out direct compression tests with cylinders of $150 \mathrm{~mm}$ diameter and $300 \mathrm{~mm}$ height, according to EN 206-1 (2000). In the tested beams, high bond steel bars of $6,12,16$ and $32 \mathrm{~mm}$ diameter were used. The values of their main tensile properties were obtained from uniaxial tensile tests performed according to the recommendations of EN 10002-1 (1990). The tensile properties of the CFK 150/2000 S\&P laminates were characterized by uniaxial tensile tests carried out according to ISO 527-5 (1997). Table 2 includes the average values obtained from these experimental programs. According to this table, the properties of the steel and CFRP are similar in the two types of beams (beams with the higher and lower concrete strength). The MBrace Resin 220 (Degussa 2003) epoxy adhesive was used to bond the laminates to the concrete.

Table 1. Shear reinforcement configurations of the tested beams.

\begin{tabular}{|c|c|c|c|c|c|}
\hline \multirow{2}{*}{$\begin{array}{c}\text { Number of } \\
\text { laminates }\end{array}$} & \multirow{2}{*}{$\begin{array}{c}\text { CFRP } \\
\text { angle } \\
{\left[\theta_{f}\right]^{\text {a }}} \\
\left({ }^{\circ}\right) \\
\end{array}$} & \multirow{2}{*}{$\begin{array}{c}\text { CFRP } \\
\text { spacing } \\
{\left[s_{f}\right]} \\
(\mathrm{mm}) \\
\end{array}$} & \multirow{2}{*}{$\begin{array}{c}\text { CFRP } \\
\text { percentage } \\
{\left[\rho_{f}\right]^{\mathrm{b}}} \\
(\%)\end{array}$} & \multicolumn{2}{|c|}{ Percentage of steel stirrups } \\
\hline & & & & $\rho_{s w}=0.10 \%^{\mathrm{c}}$ & $\rho_{s w}=0.17 \%^{\mathrm{d}}$ \\
\hline $2 \times 4$ & 45 & 275 & 0.08 & 2S-4LI45 & 4S-4LI45 \\
\hline $2 \times 4$ & 60 & 243 & 0.07 & 2S-4LI60 & 4S-4LI60 \\
\hline $2 \times 7$ & 90 & 114 & 0.13 & $2 \mathrm{~S}-7 \mathrm{LV}$ & $4 \mathrm{~S}-7 \mathrm{LV}$ \\
\hline $2 \times 7$ & 45 & 157 & 0.13 & 2S-7LI45 & 4S-7LI45 \\
\hline $2 \times 6$ & 60 & 162 & 0.11 & 2S-6LI60 & 4S-6LI60 \\
\hline
\end{tabular}

angle between the CFRP fiber direction and the beam axis; ${ }^{\mathrm{b}}$ The CFRP percentage was obtained from $\rho_{f}=\left(2 a_{f} b_{f}\right) /\left(b_{w} s_{f} \sin \theta_{f}\right)$ being $a_{f}=1.4 \mathrm{~mm}$ and $b_{f}=9.5 \mathrm{~mm}$ the dimensions of the laminate cross section and $b_{w}=180 \mathrm{~mm}$ is the beam web width; ${ }^{\mathrm{c}} 2 \mathrm{~S}-\mathrm{R}$ is the reference beam without CFRP (Fig. 3); ${ }^{\mathrm{d}} 4 \mathrm{~S}-\mathrm{R}$ is the reference beam without CFRP (Fig. 3).

Table 2. Values of the properties of intervening materials.

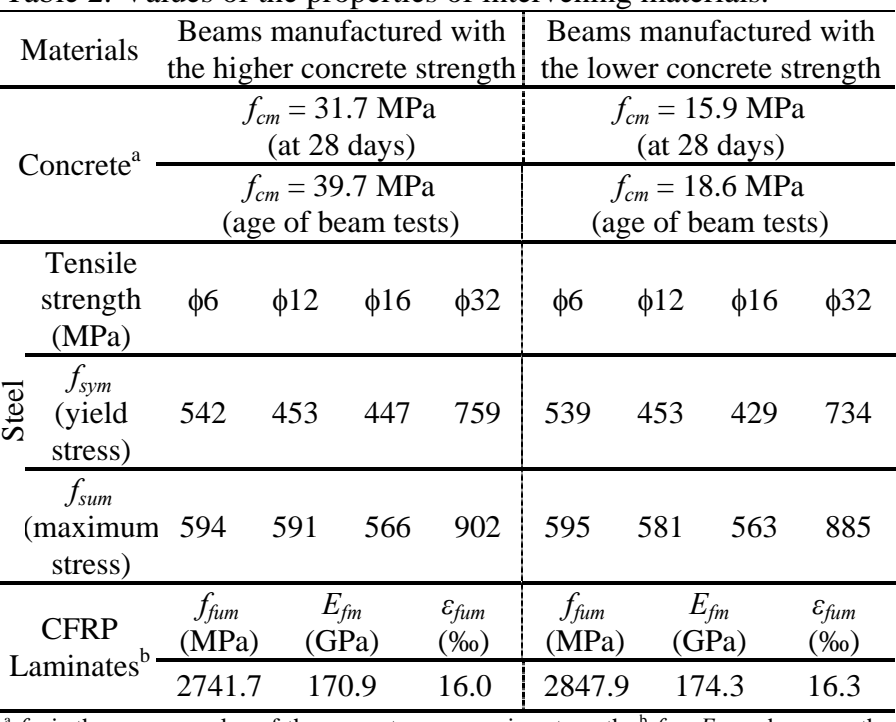

${ }^{\mathrm{a}} f_{c m}$ is the average value of the concrete compressive strength; ${ }^{\mathrm{b}} f_{\text {fum }}, E_{f m}$ and $\varepsilon_{f u m}$ are the maximum tensile strength, Young's modulus and maximum strain of the CFRP laminates.

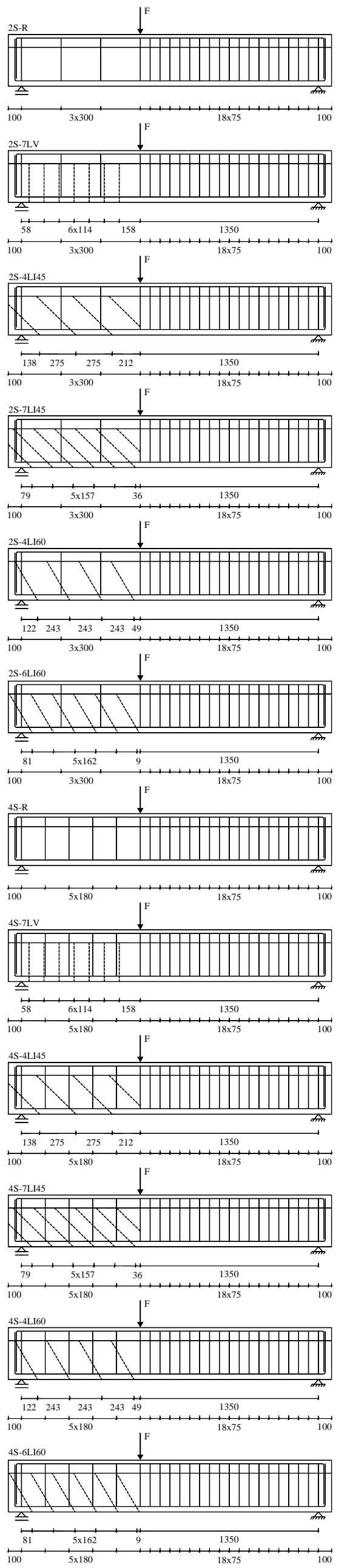

Figure 3. Localization of the steel stirrups (continuous line) and CFRP laminates (dashed line) (dimensions in mm). 


\subsection{Discussion of tests results}

The recorded force-displacement diagrams $(F-u)$ in the loaded section obtained for the tested beams are reported in Figure 4.
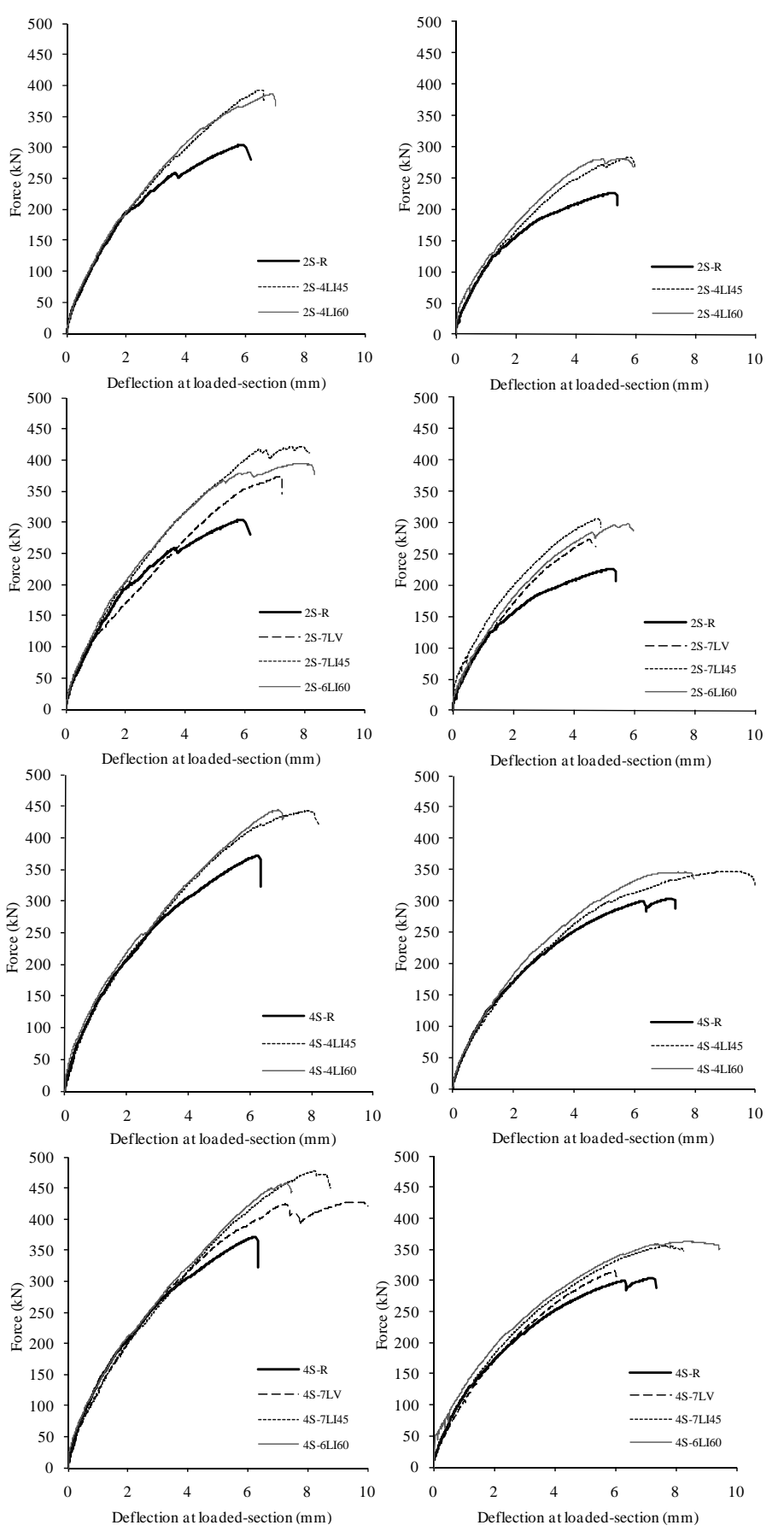

Figure 4. Force vs deflection at the loaded-section for the tested beams (left part: beams with $f_{c m}=39.7 \mathrm{MPa}$; right part: beams with $\left.f_{c m}=18.6 \mathrm{MPa}\right)$.

Up to critical diagonal crack (CDC) initiation the strengthened and its corresponding reference beam had similar $F-u$, regardless of the percentage of steel stirrups and the percentage and orientation of the CFRP. At CDC initiation the load decay observed in the reference beams did not occur in the CFRP shear strengthened beams, revealing that the presence of the CFRP delayed the propagation of the shear crack. This results in an increase in the beam's load carrying capacity.
The maximum load $\left(F_{\max }\right)$ and the corresponding deflection at loaded-section $\left(u_{F \max }\right)$ for all the tested beams are included in Table 3. The values of the $\Delta F_{\max } / F_{\max }^{\text {ref }}$ ratio (gain due to CFRP where $\Delta F_{\max }=F_{\max }-F_{\max }^{r e f}$ and $F_{\max }^{r e f}$ is the maximum force of reference beam) for the beams with $f_{c m}=39.7 \mathrm{MPa}$ and $f_{c m}=18.6 \mathrm{MPa}$ are included in Table 3 and represented in Figure 5, being visible the increase of the NSM effectiveness with the increase of the concrete strength. According to the values into Table 3, the average value of the $\Delta F_{\max } / F_{\max }^{\text {ref }}$ ratio for NSM arrangements adopted in beams with higher and lower concrete compressive strength was $26.5 \%$ and $22.4 \%$, respectively (the values regarding the $4 \mathrm{~S}$ 7LV shear strengthening configuration was excluded for this analysis). Independently of the concrete strength and the percentage of existing steel stirrups, the inclined laminates were more effective than vertical laminates. An increase of the percentage of CFRP produced an increase of the shear strengthening contribution.

In general the failure modes of the tested beams with CFRP have been influenced by the concrete strength, since at failure a certain concrete volume was attached to the laminates (concrete fracture). This justifies the better shear strengthening contribution of the CFRP in the beams with $f_{c m}=39.7 \mathrm{MPa}$. The failure modes of the beams with NSM laminates are also influenced by the percentage of the CFRP. In some beams with the higher percentage of CFRP a detrimental group effect (Fig. 6) between neighboring laminates occurred that originated a separation of parts of the concrete cover, which had already been observed in previous experimental programs (Barros and Dias 2006; Rizzo and De Lorenzis 2009; Dias and Barros 2009) and analytical research (Bianco et al. 2009).

Table 3. Relevant results of the load capacity up to beam's failure.

\begin{tabular}{|c|c|c|c|c|c|c|c|c|}
\hline & $\begin{array}{c}\text { Beams } \\
\left(\rho_{s w}=0.10 \%\right)\end{array}$ & $\begin{array}{l}F_{\max } \\
(\mathrm{kN})\end{array}$ & $\begin{array}{c}\text { Gain } \\
\text { due to } \\
\text { CFRP } \\
(\%)\end{array}$ & $u$ & $\rho_{s w}=$ & $\begin{array}{l}F_{\max } \\
(\mathrm{kN})\end{array}$ & $\begin{array}{c}\text { Gain } \\
\text { due to } \\
\text { CFRP } \\
\text { (\%) }\end{array}$ & $2 x$ \\
\hline \multirow{6}{*}{ 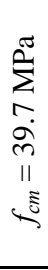 } & $2 S-R$ & 303.8 & - & 5.88 & $4 S-R$ & 371.4 & - & 6.25 \\
\hline & 2S-4LI45 & 392.8 & 29.3 & 6.45 & 4S-4LI45 & 442.5 & 519.1 & 7.93 \\
\hline & 2S-4LI60 & 386.4 & 27.2 & 6.90 & 4S-4LI60 & 443.8 & 319.5 & 6.91 \\
\hline & 2S-7LV & 374.1 & 23.1 & 7.17 & 4S-7LV & 427.4 & 415.1 & 9.75 \\
\hline & 2S-7LI45 & 421.7 & 38.8 & 7.93 & 4S-7LI45 & 478.1 & 28.7 & 8.26 \\
\hline & 2S-6LI60 & 394.4 & 29.8 & 7.87 & 4S-6LI60 & 457.6 & 23.2 & 7.31 \\
\hline \multirow{6}{*}{$\begin{array}{l}\sum_{0}^{\pi} \\
0 \\
\infty \\
+1 \\
11 \\
5\end{array}$} & $2 S-R$ & 226.5 & - & 5.29 & $4 S-R$ & 303.8 & - & 7.20 \\
\hline & 2S-4LI45 & 283.0 & 24.9 & 5.79 & 4S-4LI45 & 347.2 & 214.3 & 9.28 \\
\hline & 2S-4LI60 & 281.6 & 24.3 & 5.57 & 4S-4LI60 & 345.6 & 513.8 & 7.67 \\
\hline & 2S-7LV & 273.7 & 20.8 & 4.55 & 4S-7LV & 315.2 & 23.8 & 5.98 \\
\hline & 2S-7LI45 & 306.5 & 35.3 & 4.79 & 4S-7LI45 & 356.4 & 417.3 & 7.83 \\
\hline & 2S-6LI60 & 297.7 & 31.4 & 5.84 & 4S-6LI60 & 362.3 & 319.3 & 8.36 \\
\hline
\end{tabular}

Figure 5 also shows that the amount of existing steel stirrups plays a very important role on the effectiveness of the NSM shear strengthening tech- 
nique with CFRP laminates. In fact, the effectiveness of the CFRP was higher in the beams with the lower percentage of steel stirrups analysed $\left(\rho_{s w}=\right.$ $0.10 \%)$. According to Figure 5, for an increase from $0.10 \%$ to $0.17 \%$ in the percentage of steel stirrups in the $\mathrm{L}_{\mathrm{i}}$ beam span (about 70\%), the NSM strengthening effectiveness decreased in about $70 \%$ and $55 \%$ (the value regarding the solution with vertical laminates was excluded for this evaluation) for the beams with $f_{c m}=39.7 \mathrm{MPa}$ and $f_{c m}=18.6 \mathrm{MPa}$, respectively. It emerges that a formulation for the prediction of the NSM shear strengthening contribution cannot neglect the percentage of existing steel stirrups.
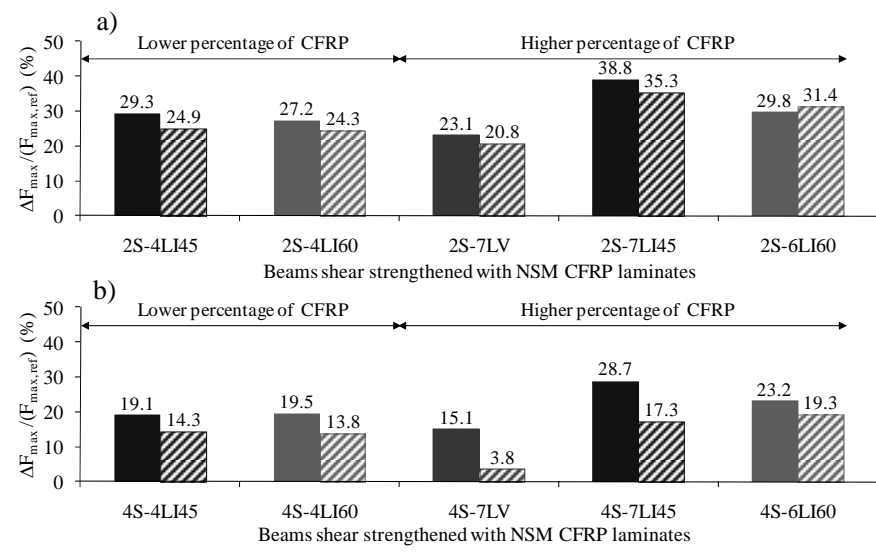

Figure 5. Concrete strength influence in the effectiveness of the NSM shear strengthening technique with CFRP laminates (left column: $f_{c m}=39.7 \mathrm{MPa}$; right column: $f_{c m}=18.6 \mathrm{MPa}$ ): a) beams with $\rho_{s w}=0.10 \%$; b) beams with $\rho_{s w}=0.17 \%$.

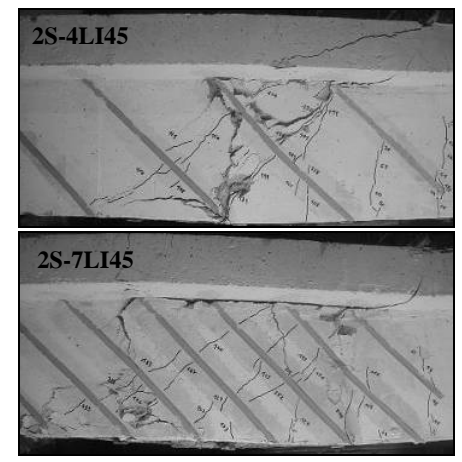

Figure 6. Influence of CFRP percentage on failure modes (beams with $f_{c m}=18.6 \mathrm{MPa}$ ).

\section{CONCLUSIONS}

The following conclusions can be obtained from the experimental results:

- The NSM CFRP laminates shear strengthening technique is still effective in beams of concrete with an average compressive strength of $18.6 \mathrm{MPa}$ at the age of the tests, which can be considered as the lowest concrete strength class for structural purposes. The CFRP shear strengthening configurations provided an increase not only in terms of maximum load, but also in terms of load carrying capacity after shear crack formation. The concrete strength has an important role on the effectiveness of the NSM shear strengthening technique, since this effectiveness decreases with the decrease of the concrete strength. In fact, when the same NSM CFRP laminates arrangements were applied in a group of beams of concrete compressive strength $\left(f_{c m}\right)$ equal to $39.7 \mathrm{MPa}$ and in another group of beams of $f_{c m}=18.6 \mathrm{MPa}$, the CFRP laminates were more effective in the former beams.

- Inclined laminates were more effective than vertical laminates and an increase of the percentage of laminates led to an increase of the shear capacity of the beams. A detrimental effect of the increase of the percentage of the existing steel stirrups exists in terms of the effectiveness of the NSM technique for the shear resistance of RC beams.

- An analytical formulation for the prediction of the NSM shear strengthening contribution should take into account the concrete mechanical properties, the percentage and orientation of the CFRP and the percentage of the existing steel stirrups.

\section{ACKNOWLEDGEMENTS}

The authors wish to acknowledge the support provided by the "Empreiteiros Casais", Degussa, S\&P ${ }^{\circledR}$ and Secil (Unibetão, Braga). The study reported in this paper forms a part of the research program supported by FCT, PTDC/ECM/73099/2006.

\section{REFERENCES}

Barros, J.A.O. \& Dias, S.J.E. 2006. Near surface mounted CFRP laminates for shear strengthening of concrete beams. Journal Cement and Concrete Composites 28(3): 276-292.

Bianco, V.; Barros, J.A.O.; Monti, G. 2009. Three dimensional mechanical model for simulating the NSM FRP strips shear strength contribution to RC beams. Engineering and Structures Journal 31(4): 815-826.

Degussa Construction Chemicals Portugal. 2003. Technical Report MBrace Resin 220.

Dias, S.J.E. \& Barros, J.A.O. 2009. Performance of reinforced concrete $\mathrm{T}$ beams strengthened in shear with NSM CFRP laminates. Engineering Structures doi:10.1016/j.engstruct.2009.10.001.

EN 206-1. 2000. Concrete - Part 1: Specification, performance, production and conformity. European standard, CEN: 69pp.

EN 10002-1. 1990. Metallic materials - Tensile testing. Part 1: Method of test (at ambient temperature). European Standard, CEN: 35pp.

ISO 527-5. 1997. Plastics - Determination of tensile properties - Part 5: Test conditions for unidirectional fibre-reinforced plastic composites. International Organization for Standardization (ISO): 9 pp.

Rizzo, A. \& De Lorenzis, L. 2009. Behaviour and capacity of RC beams strengthened in shear with NSM FRP reinforcement. Construction and Building Materials 23: 1555-1567. 